[17]. O. A. Aimakov, D. K. Seitkalieva, N. I. Svincickaia, Proceedings of International Conference "Chemistry, Chemical Engineering and Biotechnology at the turn of the millennium," Tomsk, 2003, vol.1, p. 193-194.

[18]. O. A. Aimakov, Proceedings of the scientific conference devoted to the 185th anniversary of the St. Petersburg State Technical Institute Russia, SaintPetersburg, 2013, p. 68-70.

[19]. O. A. Aimakov, N. M. Zubova, Scientific collection "Problems of development of new drugs." Publishing house "Guillem" .Ufa, 2003, p. 35-37.
[20]. O. A.Aimakov, K. B. Erzhanov, T. A. Mastriukova. News of RSA, chem.ser., 2003, №1,.p. 2276-2279.

[21]. O. A. Aimakov, K. B. Erzhanov, T. A. Mastriukova, News of RSA, Che.ser., 1998, №8 p. 1876-1878.

[22]. O. A. Aimakov, S. A. Duisembaev, T. A, Mastriukova, K. B. Erzhanov, News of MS-SA RK, Chem.ser., 1996, №5, p. 68-717.

[23]. O. A. Aimakov, K. B. Erzhanov, T. A. Mastriukova, Scientific collection "State and Prospects of Development of Organic Chemistry", Almaty, 2002, p. 31-32.77

\title{
ИЗОТОПНАЯ СЕЛЕКТИВНОСТЬ ГИДРАТАЦИИ ПЕРОКСИДА КАЛЬЦИЯ
}

DOI: $\frac{10.31618 / \text { ESU.2413-9335.2019.1.65.262 }}{\text { Сапожников Ю.А. }}$
д.х.н., вед.н.с., химический факультет МГУ имени М.В. Ломоносова

Сапожникова Л.Д.

Инженер, д.х.н., вед.н.с., химический факультет МГУ имени М.В. Ломоносова

\section{THE ISOTOPIC SELECTIVITY OF THE HYDRATION OF CALCIUM PEROXIDE}

Sapozhnikov Yu.A., Sapozhnikova L.D.

\section{АННОТАЦИЯ}

Экспериментально показано, Что при взаимодействии с водой, загрязненной тритием, безводный пероксид кальция проявляет изотопную селективность, формируя гидратную оболочку образующегося труднорастворимого октагидрата кальция из протиевой воды и оставляя тритиевую воду в жидкой фазе.

\section{ABSTRACT}

It has been shown experimentally, that during an interaction with water, contaminated with tritium, anhydrous calcium peroxide exhibits isotopic selectivity, forming a hydrated shell of the produced insoluble calcium octahydrate from protium water and leaving tritium water in the liquid phase.

Ключевые слова: Пероксид кальция, гидратация, изотопная селективность, Фукусима

Keyword: Calcium peroxide, hydration, isotopic selectivity, Fukushima

Для разделения изотопов водорода известны многие методы, основанные на различиях свойств их соединений, таких как температура плавления и кипения, потенциал ионизации и др. [2, 3]. Реализация этих в принципе несложных подходов требует, однако, сравнительно непростой аппаратуры, использования дорогих катализаторов на основе палладия или платины, больших затрат труда, времени и электроэнергии.

В настоящей работе описываются результаты исследования взаимодействия безводного пероксида кальция (ПОК) с водой, загрязненной тритием. Известно [1], что при гидратации ПОК образуется труднорастворимый октагидрат пероксида кальция (ОГ ПОК) $\mathrm{CaO} 2 \cdot 8 \mathrm{H} 2 \mathrm{O}$.

Пероксид кальция - продукт крупнотоннажного производства химической промышленности. Его использование основано, главным образом, на способности испускать кислород при медленном разложении:

$$
\mathrm{CaO}_{2}+\mathrm{H}_{2} \mathrm{O} \rightarrow \mathrm{Ca}(\mathrm{OH})_{2}+1 / 2 \mathrm{O}_{2}
$$

Кислород in statu nascendi воздействует на корневые системы растений, что ведет к повышению урожайности почв, может обеззараживать воды и почвы и имеет множество других областей применения.

В экспериментальной работе использовался технический ПОК, синтезированный в Институте Общей и Неорганической Химии РАН и содержащий довольно высокий процент примесей (до $40 \%$ ), таких как карбонат и оксид кальция и др. Как показали экспериментальные исследования авторов, при добавлении безводного ПОК к воде, содержащей тритий, для формирования гидратной оболочки ПОК использует только молекулы протиевой воды. В результате удельная активность трития в жидкой фазе над осадком ОГ ПОК повышается с увеличением массы добавляемого ПОК (Рисунок $1)$. 


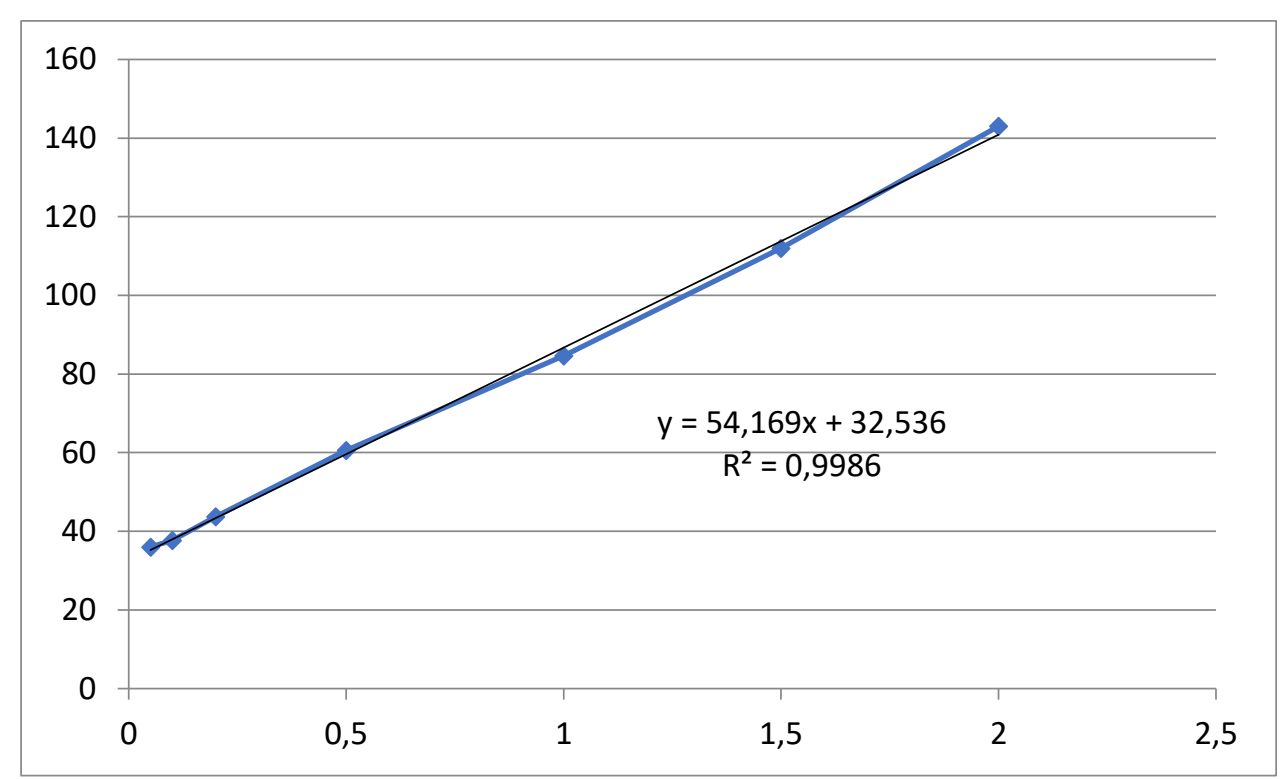

Рисунок 1. Зависимость удельной активности трития в жидкой фазе (Бк/мл) От массы добавленного безводного пероксида кальияия (2).

Другими словами процесс гидратации пероксида кальция проявляет изотопную селективность.

Измерение радиоактивности трития выполнялось на жидкостно-сцинтилляционном анализаторе Tri-Carb 2810-TR (PerkinElmer) c использованием жидкого сцинтиллятора Ultima Gold той же фирмы.

По-видимому, наблюдаемый эффект может использоваться для отделения трития от больших объемов морской или солоноватой воды при ликвидации последствий аварии на АЭС Дай-Ичи в префектуре Фукусима (Япония) [4].

Очевидно, разработка экономически эффективного сорбента для извлечения трития из весьма больших объемов загрязненной им воды (сотни бочек из нержавеющей стали объёмом около $100 \mathrm{M}^{3}$ ) вряд ли даст положительный результат, т.к. молекулы протиевой воды более подвижны, чем тритиевой, и протий образует более прочные связи, чем тритий. Стерический фактор в таком процессе также уменьшает вероятность сорбции трития по сравнению с протием на сорбенте любой природы.

Практическая реализация отделения тритиевой воды от больших масс загрязненных тритием природных вод с использованием ПОК может быть выполнена, например, путем вскрытия бочек, в которых до сих пор хранится морская или солоноватая вода, и добавления в них безводного ПОК при интенсивном перемешивании. Октагидрат пероксида кальция пойдет на дно, а над осадком останется вода, обогащенная тритием. Эта вода должна откачиваться для последующего хранения в емкостях существенно меньшего объема.

Производительность системы в целом зависит от того, насколько четко удастся разделить объемы твердой и жидкой фаз.

Отметим, что изотопная селективность процесса гидратации ПОК может быть отнесена к фундаментальным явлениям, позволяющим ожидать новых интересных результатов.

Авторы благодарят Т.А. Трипольскую (Институт Общей и Неорганической Химии), Б.В. Егорову (каф. радиохимии Химфака МГУ имени М.В. Ломоносова), и всех других, кто помогал им в выполнении этой работы, а также доктора Хиромото Оно и его коллег (Chemical Force Co., Ltd., Япония) за интерес к этой работе.

\section{ЛИТЕРАТУРА}

1.Гладышев Н.Ф., Гладышева Т.В, Лемешева Д.Г. и др. Пероксидные соединения кальция. Синтез. Свойства. Применение // 2013, М.: Издательский дом «Спектр», с. 216

2.Мосин О.В. Очистка воды от тяжелых изотопов дейтерия, трития и кислорода. СОК (Сантехника, отопление, кондиционирование) // 2012

3. Пятницкий Н.В., Поляков В.А. Электролитическое обогащение водных проб с низкими концентрациями трития. Водные ресурсы. 1983 // т. 10, №5, cc. 137-141.

3. Povinec P.P., Hirose K., Aoyama M. Fukushima Accident: Radioactivity Impact on the Environment. 2013 // Elsevier, p. 382. 